\title{
Un dato más para la historia de la difusión de la leyenda de la destrucción de Jerusalén
}

\section{Another Fact for the History of the Diffusion of the Jerusalem's Destruction Leyend}

\author{
DAvid Hook \\ University of Oxford \\ david.hook@mod-langs.ox.ac.uk
}

\begin{abstract}
A la evidencia ya conocida para la difusión en Hispanoamérica de la leyenda medieval de la destrucción de Jerusalén por los romanos podemos añadir una referencia en un documento notarial de Lima, 1583, en el cual el librero Juan Ximénez del Río pide que le traigan desde España veinte ejemplares de dicho texto.
\end{abstract}

Palabras Clave: historia del libro, comercio transatlántico de libros, protocolos notariales, leyendas piadosas medievales, versiones hispánicas de la Destrucción de Jerusalén

To the existing evidence for the presence of the medieval legend of the Roman destruction of Jerusalem in Hispanic America may be added a reference in a notarial document from Lima in 1583, ordering twenty copies of the text from Spain for the bookseller Juan Ximénez del Río.

KeYwORDs: history of the book, Transatlantic book trade, notarial records, medieval pious legends, Hispanic texts of Destrucción de Jerusalén

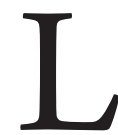

os estudios de varios autores sobre la historia de la difusión de la leyenda de la destrucción de Jerusalén por los romanos han establecido la importancia de este tema medieval en las letras hispánicas a través de los siglos (por ejemplo, Lida de Malkiel, Jerusalén; Hook, “The Legend”). Sin embargo, en el siglo XVI son escasos los testimonios de la existencia de la leyenda en Hispanoamérica; el más conocido es una alusión en la Historia verdadera de Bernal Díaz del Castillo (Díaz, Historia verdadera, II, 64; Lida de Malkiel, Jerusalén, 111, 190 nota c; Hook, “The Legend”, 116, 127 nota 25). 
Nos ofrece una prueba contundente de la difusión del tema en México la existencia de una versión náhuatl de La destrucción de Jerusalén y basada en una forma de la leyenda publicada en la colección de textos piadosos bajo el título general de Gamaliel, pero esta etapa del uso del tema es algo posterior (Paso y Troncoso, Destrucción; Hook, “The Auto”, 335-341).

Sin embargo, en un documento del 22 de febrero de 1583, emitido en Lima, y publicado por Irving A. Leonard, encontramos una referencia al Libro de la destruición de Jerusalén que, según parece, no se había identificado antes como tal, porque el título no había sido reconocido bien por haberse confundido varias letras (Leonard, Books of the Brave, 357, núm. 139). En la fecha indicada, se redactó un acuerdo entre el librero Juan Ximénez del Rio y un tal Francisco de la Hoz, viajero a España, según el cual éste iba a traer consigo, al regresar de España al Perú, una cantidad determinada de libros para la librería del contratante (Archivo Nacional del Perú, Protocolos de Alonso Hernández, 1566-1583, fol. 1419-1422). Entre los títulos especificados se encuentra una referencia a "20 discrecion de Jerusalen en pergamino", obra no identificada por Leonard. No conozco ninguna obra de este título entre la producción de los tórculos hispánicos de la época. Evidentemente se trata de un error ocasionado por confusión paleográfica, y en vez de discrecion debe leerse destruición o destrucción. No fue ésta la primera ocasión en que se había producido una lectura confusa al catalogar dicha obra; puede citarse un inventario catalán del año 1510 en el que se registra, según la edición moderna, "un libre sotill appellat Deffinittio de Jherusalem, de mà" (Junyent, "Repertorio”, 75 núm. 202).

No sé si se cumplió el encargo, y por lo tanto es imposible afirmar que los veinte ejemplares del Libro de la destrucción de Jerusalén pedidos por Ximénez del Rio llegaron en efecto a Lima. Pero el mero hecho de haberse pedido dicha cantidad de ejemplares es importante, porque atestigua que durante la segunda mitad del siglo XVI la obra debía ser asequible en el tráfico comercial de los libreros, o bien que en Lima existía la impresión de que todavía pudiera obtenerse en España; y que un librero de la capital virreinal peruana estimaba rentable la adquisición para sus existencias de una veintena de ejemplares de alguna edición de nuestra leyenda para la venta al público. La forma más conocida de la leyenda venía imprimiéndose en España como obra independiente desde el último decenio del siglo XV — nótese, por ejemplo, la presencia de 671 ejemplares de una edición desconocida del Libro de la destruición de Jerusalén, probablemente impresa por Jacobo Cromberger, entre las existencias de la librería de éste según el inventario del 7 de junio de 1529 - pero no se ha identificado (que yo sepa) ningún ejemplar conservado 
de una edición del siglo xvi (Hook, “The Legend”, 113-14, 124-25 notas 4-7). El documento peruano sugiere que quizás la difusión de la obra haya sido más duradera y extendida de lo que se venía imaginando, a pesar de las prohibiciones del Index, bajo las cuales cayeron las ediciones del Gamaliel a partir de 1551 (Hook, “The Auto", 336, 344; Bujanda, Index, 251-252), y que la producción de ediciones impresas del Libro de la destruición de Jerusalén se haya extendido por lo menos hasta la segunda mitad del siglo XVI.

\section{BIBLIOGRAFÍA}

Bujanda, J. M. DE, Index de l'Inquisition espagnole, 1551, 1554, 7559, Sherbrooke y Genève: Droz, 1984.

Díaz del CAstillo, Bernal, Historia verdadera de la conquista de la Nueva España, ed. de J. Ramírez Cabañas, 2 tomos, $5^{\text {a }}$ ed., México: Porrúa, 1960.

Hoor, David, “The Auto de la destruición de Jerusalén in Relation to its Source”, Bulletin of Hispanic Studies, 51, 1974, 335-345.

Hook, David, "The Legend of the Flavian Destruction of Jerusalem in Late Fifteenth-century Spain and Portugal”, Bulletin of Hispanic Studies, 65, 1988, 113-128.

JUNYENT, EDUARDO, "Repertorio de noticias sobre manuscritos catalanes entresacados de algunos inventarios de la 'curia fumada' de Vich”, Analecta Sacra Tarraconensia, 16, 1943 [1944], 57-86.

LEONARD, IRVING A., Books of the Brave, being an account of books and of men in the Spanish conquest and settlement of the' sixteenth-century New World, nueva ed. con una introd. por Rolena Adorno, Berkeley: University of California Press, 1992 [1ª ed., 1949].

Lida de Malkiel, María Rosa, Jerusalén. El tema literario de su cerco y destrucción por los romanos, Buenos Aires: Universidad de Buenos Aires, 1973.

Paso y Troncoso, Francisco Del, Destrucción de Jerusalén, auto en lengua mexicana (anónimo), escrita con letra de fines del siglo XVII, Florencia: el autor, 1907 (Biblioteca Náhuatl, I, Cuaderno 4). 
